\title{
Adult mice lacking Mct8 and Dio2 proteins present alterations in peripheral thyroid hormone levels and severe brain and motor skill impairments
}

Soledad Bárez-López ${ }^{1,2}$, Carmen Grijota-Martínez ${ }^{1,2}$, Eva Ausó ${ }^{1,3}$, Mario Fernández-deFrutos $^{1,4}$, Ana Montero-Pedrazuela ${ }^{1}$ and Ana Guadaño-Ferraz ${ }^{1,2}$

1 Instituto de Investigaciones Biomédicas Alberto Sols, Consejo Superior de Investigaciones Científicas (CSIC)-Universidad Autónoma de Madrid (UAM), Arturo Duperier 4, E-28029 Madrid, Spain

2 Center for Biomedical Research On Rare Diseases (Ciberer), Unit 708, Instituto de Salud Carlos III, Madrid, Spain

3 Universidad de Alicante, Departamento de Óptica, Farmacología y Anatomía. Carretera San Vicente del Raspeig s/n, 03690 Alicante, Spain

4 Present address: IMDEA Research Institute on Food and Health Sciences. 28049 Madrid, Spain.

Soledad Bárez-López (PhD). Corresponding author.

Address: Department of Endocrine and Nervous System Pathophysiology, Instituto de Investigaciones Biomédicas Alberto Sols, Consejo Superior de Investigaciones CientíficasUniversidad Autónoma de Madrid, Arturo Duperier 4, E-28029 Madrid, Spain Telephone: +34915854465

Email: soledad.barez@gmail.es

Carmen Grijota-Martínez (PhD)

Address: Department of Endocrine and Nervous System Pathophysiology, Instituto de Investigaciones Biomédicas Alberto Sols, Consejo Superior de Investigaciones CientíficasUniversidad Autónoma de Madrid, Arturo Duperier 4, E-28029 Madrid, Spain Telephone: +34915854465

Email: cgrijota@iib.uam.es 
Eva Ausó (PhD)

Universidad de Alicante, Departamento de Óptica, Farmacología y Anatomía. Carretera San Vicente del Raspeig s/n, 03690 Alicante, Spain

Telephone: +34965903666

Email: eausomonreal@gmail.com

Mario Fernández-de-Frutos (MSc)

IMDEA Research Institute on Food and Health Sciences. Carretera de Canto Blanco no 8 , E28049 Madrid, Spain.

Telephone: +34917278100

Email: mario.fernandez@imdea.org

Ana Montero-Pedrazuela (PhD)

Address: Department of Endocrine and Nervous System Pathophysiology, Instituto de Investigaciones Biomédicas Alberto Sols, Consejo Superior de Investigaciones CientíficasUniversidad Autónoma de Madrid, Arturo Duperier 4, E-28029 Madrid, Spain

Telephone: +34915854465

Email: amontero@iib.uam.es

Ana Guadaño-Ferraz (PhD). Corresponding author.

Address: Department of Endocrine and Nervous System Pathophysiology, Instituto de Investigaciones Biomédicas Alberto Sols, Consejo Superior de Investigaciones CientíficasUniversidad Autónoma de Madrid, Arturo Duperier 4, E-28029 Madrid, Spain

Telephone: +34 915854494

Email: aguadano@iib.uam.es

Running title: Impairments in Mct8- and Dio2- deficient mice.

Key words: Mct8 deficiency, deiodinase type 2, mouse model, motor skills impairments, histological brain impairments. 
Abstract

Background: Mutations in the thyroid hormone transporter monocarboxylate transporter

8 (MCT8) lead to peripheral hyperthyroidism and profound psychomotor alterations in humans. Mice lacking Mct8 present peripheral hyperthyroidism but no gross neurological abnormalities due to brain compensatory mechanisms involving the enzyme deiodinase type 2 (Dio2).

Methods: Here we have analyzed the endocrine and neurologic phenotype of mice lacking both Mct8 and Dio2 at 3 and 6 months of age. T4 and T3 levels/content were measured by specific radioimmunoassays; motor skill performance was evaluated by the footprint, rotarod, four limb hanging wire and balance beam tests; and brain histological analysis was performed by immunostaining for neurofilament and parvalbumin.

Results: We have found that this mouse model presents peripheral hyperthyroidism and brain hypothyroidism. Interestingly, the severity of the brain hypothyroidism seems permanent and varies across regions, with the striatum being a particularly affected area. We have also found brain alterations at the histological level compatible with thyroid hormone deficiency, and impaired motor skills.

Conclusions: These findings indicate the potential of Mct8/Dio2-deficient mice to represent a model for human MCT8 deficiency, to understand the mechanisms underlying its pathophysiology and ultimately design therapeutic interventions for human patients. 


\section{Introduction}

Mutations in the monocarboxylate transporter 8 (MCT8, SLC16A2) gene, located on the $\mathrm{X}$ chromosome, are associated with the orphan and rare disease Allan-Herndon-Dudley syndrome (AHDS) in males (1-3). The MCT8 is highly specific in transporting thyroid hormones (TH), thyroxine (T4) and its nuclear active form 3,5,3'triiodothyronine (T3). MCT8-deficient patients present global developmental delay, profound intellectual disability, lack of speech and poor communication skills, as well as severe neuromotor impairments with central hypotonia, progressive spastic quadriplegia and dystonic movements (4-13). These patients also present thyroid function test abnormalities, consisting of high serum T3, low T4 and reverse T3 (rT3), and normal to slightly elevated thyrotropin $(\mathrm{TSH})(2,3)$. Studies from mice and patient-specific induced pluripotent stem cells indicate that an impaired TH transport across the brain barriers, including the bloodbrain barrier (BBB), is an important pathophysiological mechanism in MCT8 deficiency (1416) leading to decreased T4 and T3 content in the brain (17-19). Indeed, strong evidences of brain hypothyroidism have been found in the brain of MCT8-deficient subjects at prenatal and postnatal ages (19).

Mct8 knockout (Mct8KO) mice were generated as a model for the AHDS. These mice faithfully replicate the alterations in the circulating $\mathrm{TH}$ concentrations of patients, with high T3 and low T4 $(17,18)$. Unfortunately, they do not present gross neurological abnormalities (20); hence they are only a partial model of the disease. Despite of this, they have been a useful tool to understand some aspects of the syndrome and to explore the differences between mice and humans. The current theory that explains why Mct8KO mice do not present gross neurological abnormalities, unlike patients, supports that increased deiodinase type 2 (Dio2) activity in the brain of $\operatorname{Mct8KO}$ mice $(17,18,21)$ enhances local T4 to T3 conversion as a compensatory mechanism. In Mct8KO mice T3 but not T4 transport is impeded at the BBB (14), therefore it was postulated that T4 crosses the BBB and/or the blood-cerebrospinal fluid barrier (BCSFB) in the absence of Mct8 through a transporter not present in humans. The organic anion transporting polypeptide 1c1 (Oatp1c1) transporter was proposed as a candidate to mediate T4 transfer into the mouse brain, as it is predominantly localized in capillary endothelial cells and in choroid plexus structures (22- 
24) and most importantly, OATP1C1 expression is weak at the BBB endothelial cells of primate (25) and human (26) brain.

This hypothesis is supported by the phenotype observed in double knockout (KO) animals lacking both Mct8 and Dio2 proteins or Mct8 and Oatp1c1 transporters, as both animal models presented similar characteristics to hypothyroidism with decreased T3 content and altered expression of T3-target genes in the brain $(21,27)$. Further characterization of double Mct8/Oatp1c1KO mice revealed that these animals present impaired motor skills with abnormal gait, poor coordination and reduced grip strength; disturbed cerebellar development; reduced myelination and compromised GABAergic interneurons. Moreover, they also replicate the patient's thyroid function tests (27) so they have been considered the animal model most closely reflecting human MCT8-deficient patients.

Even though Mct8/Oatp1c1KO mice somehow reflect human MCT8 deficiency, there are some limitations within this model. For instance, Oatp1c1 also transports other compounds including steroid hormone metabolites such as the conjugated sterol $\beta$ estradiol-17- $\beta$-glucuronide (28), so the phenotypic outcome of these animals could also be due to alterations in the transport of other molecules. Furthermore, mutations in the OATP1C1 transporter in humans have been related to brain hypometabolism, brainspecific hypothyroidism and neurodegeneration (29). For these reasons, having an additional model of the syndrome would contribute to the understanding of the mechanisms that underlie MCT8 deficiency more robustly and it would be very useful to compare the effects of deficient TH signaling in the brain due to different conditions.

We propose the double Mct8/Dio2KO mice as an alternative and additional model for the AHDS. The advantage of this model versus the Mct8/Oatp1c1KO animal is that, as compensation by Dio2 activity in the absence of Mct8 is avoided in the brain, the observed phenotype will be only related to $\mathrm{TH}$ actions. The present study has been performed in young adult and adult mice because, even though it is now clear that MCT8-deficient patients present neurological alterations before birth (19), and hence patients would benefit from prenatal treatment to prevent brain damage, most patients are diagnosed within the first year after birth (there are more than 320 affected individuals belonging to 
148 families reported to date). In addition, many of the alterations found in hypothyroid rodents during the perinatal age are only transient, and therefore, the use of adult mice allows observing more persistent damage. Therefore, this study aims in the first instance to establish comparable conditions to existing patients to identify therapeutic targets, and to ultimately design therapeutic interventions that prevent or restore brain damage and simultaneously correct the thyrotoxic state in the periphery.

Here we present an extensive analysis of Mct8/Dio2KO mice at 3 and 6 months of age. As previously reported, these mice replicate the peripheral hyperthyroidism characteristic of MCT8-deficient patients and presented a reduction in the cerebral T3 content (30), as has been found in the cerebral cortex of a 30th gestational week fetus with mutations in MCT8 (19). Moreover, these mice display persistent locomotor abnormalities and brain alterations at the histological level. Based on these findings we propose the Mct8/Dio2KO mouse as an alternative and additional model to understand human MCT8 pathophysiology and to test therapeutic strategies.

\section{Material and Methods}

\section{Ethics statement}

All experimental procedures involving animals were performed following the European Union Council guidelines (directive 2010/63/UE) and Spanish regulations (R.D. 53/2013), and were approved by the ethics committee at Consejo Superior de Investigaciones Científicas (CSIC; approval number 162/17). All efforts were made to minimize suffering as indicated below.

\section{Animal models and experimental design}

All mice were housed at the Instituto de Investigaciones Biomédicas "Alberto Sols" under temperature- and light-controlled conditions at $22 \pm 2^{\circ} \mathrm{C}$ on a $12: 12$ light-dark cycle with ad libitum access to food and water. Experiments were carried out in Wild type (Wt), Mct8-deficient (Mct8KO), Dio2-deficient (Dio2KO), and double Mct8- and Dio2-deficient (Mct8/Dio2KO) male mice. Wt and Mct8KO mice were originally produced by Dumitrescu and colleagues (17) and Dio2KO mice were initially produced by Schneider and colleagues 
(31) and a colony was established at our animal facility in the same C57BL/6J genetic background. For the experiments, Wt and Mct8KO littermates were obtained by backcrossing $\mathrm{Mct8}^{-/+}$females with $\mathrm{Mct8}^{+/ \mathrm{y}}$ males, and Dio2KO and Mct8/Dio2KO male mice were obtained from $\mathrm{Mct}^{+/ \mathrm{y}} \mathrm{Dio}^{-/-}$males and $\mathrm{Mct}^{-/+} \mathrm{Diol}^{-/-}$females. Of note, in this breeding strategy, $\mathrm{Dio}^{-/-}$progenitors present high T4 plasma levels which could potentially affect the Dio2KO and Mct8/Dio2KO progeny. The Mct8 and Dio2 genotypes were confirmed by PCR of tail DNA as described (21).

Studies were conducted in 3- and 6-month-old Wt, Mct8KO, Dio2KO and double Mct8/Dio2KO mice. At 3 months of age there were no differences in the weight of the different genotypes $(\mathrm{Wt}=24.78 \pm 1.787$ grams $(\mathrm{g})$; $M c t 8 K O=23.38 \pm 2.446 \mathrm{~g}$; Dio2KO=25.00 $\pm 3.742 \mathrm{~g} ;$ Mct8/Dio2KO= $22.50 \pm 3.749 \mathrm{~g}$ ), however, at 6 months of age Mct8/Dio2KO animals had lower body weight than Wt mice $(\mathrm{Wt}=30.40 \pm 2.011 \mathrm{~g}$; Mct8KO=28.63 \pm $1.408 \mathrm{~g} ;$ Dio2KO= $33.13 \pm 2.416 \mathrm{~g} ;$ Mct8/Dio2KO= $26.75 \pm 1.581 \mathrm{~g})$.

For motor task analysis, Wt ( $\mathrm{n}=10$, from 5 litters), Mct8KO ( $\mathrm{n}=8$, from 5 litters), Dio2KO ( $\mathrm{n}$ $=8$, from 4 litters) and Mct8/Dio2KO ( $n=10$, from 4 litters) mice at 3 months of age and Wt ( $n=10$, from 5 litters), Mct8KO ( $n=8$, from 5 litters), Dio2KO ( $n=8$, from 4 litters) and Mct8/Dio2KO ( $\mathrm{n}=9$, from 4 litters) mice at 6 months of age performed the tests described in the "Motor task assessment" section.

For histological analyses of the brain, Wt ( $n=4$, from 3 litters), Mct8KO ( $n=4$, from 3 litters), Dio2KO ( $\mathrm{n}=4$, from 3 litters) and Mct8/Dio2KO ( $\mathrm{n}=4$, from 3 litters) mice at 3 months of age and Wt ( $n=4$, from 3 litters), Mct8KO $(n=4$, from 3 litters), Dio2KO ( $n=4$, from 3 litters) and Mct8/Dio2KO ( $\mathrm{n}=4$, from 3 litters) mice at 6 months of age were anesthetized with ketamine (75 $\mu \mathrm{g} / \mathrm{g}$ body weight) and medetomidine hydrochloride (1 $\mu \mathrm{g} / \mathrm{g}$ body weight) and transcardially perfused with $4 \%$ paraformaldehyde in $0.1 \mathrm{M}$ PB. Brains were removed, post-fixed overnight in the same fixative solution, cryoprotected in $30 \%$ sucrose and cut into $25 \mu \mathrm{m}$ free-floating sections in the coronal plane on a cryostat.

For hormonal determinations in plasma and tissues Wt ( $n=9$ from 6 litters), Mct8KO ( $n=9$ from 6 litters), Dio2KO ( $\mathrm{n}=7$ from 5 litters) and Mct8/Dio2KO ( $\mathrm{n}=10$ from 5 litters) mice at 3 months of age, and Wt ( $n=10$ from 5 litters), Mct8KO ( $n=8$ from 5 litters), Dio2KO ( $n$ 
$=8$ from 4 litters) and Mct8/Dio2KO ( $\mathrm{n}=9$ from 4 litters) mice at 3 months of age were anesthetized with ketamine (75 $\mu \mathrm{g} / \mathrm{g}$ body weight) and medetomidine hydrochloride (1 $\mu \mathrm{g} / \mathrm{g}$ body weight) and transcardially perfused with saline to remove blood from tissues before their collection. Prior to perfusion, blood was extracted by retroorbital collection and used for the determination of T4 and T3 plasma concentrations. Tissues (cerebral cortex, striatum and gastrocnemius muscle) were harvested.

For morphometric analysis of the thyroid gland $\mathrm{Wt}$ ( $\mathrm{n}=4$ from 1 litter) and Mct8/Dio2KO ( $n=4$ from 2 litters) mice at 6 months of age were perfused with $4 \%$ paraformaldehyde in $0.1 \mathrm{M}$ phosphate buffer. Thyroid glands attached to a section of trachea were post fixed overnight at $4 \stackrel{\circ}{\circ}$ in the same solution, washed in PBS and embedded in paraffin. Sections of thyroid glands $(8 \mu \mathrm{m})$ were stained with hematoxylin and eosin.

\section{Hormonal determinations in plasma and tissues}

High specific activity ${ }^{125} \mathrm{I}-\mathrm{T} 3$ and ${ }^{125} \mathrm{I}-\mathrm{T} 4(3000 \mu \mathrm{Ci} / \mu \mathrm{g})$ were labelled with ${ }^{125} \mathrm{I}$ (Perkin Elmer, NEZO33A) using (3-5)-T2 (Sigma, D0629) and T3 (Sigma, T2877) as substrates respectively as previously described $(32,33)$. One minor modification was the separation of the labeled products, which was done by ascending paper chromatography for $16 \mathrm{~h}$ in presence of Butanol:Ethanol:Ammonia 0.5N (5:1:2) as solvent. The ${ }^{125} \mathrm{I}-\mathrm{T} 3$ and ${ }^{125} \mathrm{I}-\mathrm{T} 4$ were eluted and kept in Ethanol at $4^{\circ} \mathrm{C}$.

T3 and T4 were extracted from individual $80 \mu \mathrm{L}$ aliquots of plasma with methanol (1:6), evaporated to dryness and taken up in the radioimmunoassay (RIA) buffer for determinations. T3 and T4 extraction from tissues (cerebral cortex, striatum and gastrocnemius), as well as determinations of T3 and T4 were performed as previously described $(34,35)$ with the dynamic range being 0.4-100 pg T3/tube and 2.5-320 pg T4/tube.

\section{Motor tasks assessment}

Footprint test. The gait of the was evaluated using the footprint test as previously described (36). The hind and the fore paws were painted with red and black non-toxic waterproof paint respectively and the animals were required to run along a tunnel $(20 \mathrm{~cm}$ 
$\times 20 \mathrm{~cm} \times 70 \mathrm{~cm}$ ) lined with paper, with a dark goal box at the end of the tunnel to encourage the mouse to run towards a dark and safe environment. Measurements for three-step cycles were averaged, considering a cycle as the distance from one pair of hind prints to the next. Footprints at the start and the end of the tunnel were excluded from the analysis as they correspond to the initiation and termination of the movement. The front base width, hind base width, forelimb stride length and hind-limb stride length were analyzed.

Rotarod test. Motor coordination and balance were evaluated with the acceleratingrotarod test as previously described (36). $60 \mathrm{~min}$ prior to the test animals were subjected to an initial training period under constant velocity. For the accelerated rotarod test, mice were placed on a rotarod (Ugo Basile, Italy) that accelerated from 4 to $44 \mathrm{rpm}$ in $3 \mathrm{~min}$ and was maintained at $44 \mathrm{rpm}$ for 2 further min. The latency of the mice to fall off the rod was recorded over the maximum observation period of $5 \mathrm{~min}$. Mice were tested for 5 consecutive days with 3 trials per day with a 20 min inter-trial interval. Data from 3 trials were averaged.

Four limb hanging wire test. Muscle strength was evaluated using the hanging wire test (37). Mice were placed on the top of a wire cage lid quadrant $(14 \times 14 \mathrm{~cm})$ that was inverted horizontally $50 \mathrm{~cm}$ above a surface with bedding. The latency to fall was recorded over a maximum period of $120 \mathrm{~s}$. Mice were tested for 2 consecutive days in one trial per day. Data from both days were averaged.

Balance beam test. Balance was evaluated as described (38). Mice were placed on the center of a horizontal wooden bar $(0.9 \mathrm{~cm}$ wide $\times 50 \mathrm{~cm}$ long) $40 \mathrm{~cm}$ above a surface with bedding. The latency to fall was recorded over a maximum period of $40 \mathrm{~s}$ and two trials were performed in one single day. The activity on the bar was rated as (0) if the mouse remained in the center of the bar or if it moved but it did not reach the ends; and (1) if the mouse reached one of the ends of the bar. 
Histological analyses

Immunohistochemical procedures were the same for anti-Parvalbumin (Pvalb; 1:1500, Sigma-Aldrich 28 P3088) and anti-Neurofilament 220KD (Nefh; 1:300, Millipore MAB5266) antibodies. Free-floating sections were incubated with $3 \%$ hydrogen peroxide and $10 \%$ methanol in PBS at RT for 15 min to block endogenous peroxidase activity. Afterwards, nonspecific antibody binding was prevented by blocking the tissue in PBS containing $0.1 \%$ triton X-100, 4\% BSA (Sigma, A4503) and 5\% normal horse serum (Vector Laboratories, S2000) at RT for $1 \mathrm{~h}$. Then, tissue sections were incubated with the primary antibodies at $4^{\circ} \mathrm{C}$ overnight in PBS containing $0.1 \%$ Triton $\mathrm{X}-100,4 \% \mathrm{BSA}$ and $1 \%$ normal horse serum. The sections were subsequently washed in PBS, and incubated for $1 \mathrm{~h}$ at RT with biotinylated secondary antibodies (Vector Laboratories) at a 1:200 dilution in PBS containing $0.1 \%$ Triton, $4 \%$ BSA and $1 \%$ normal horse serum. The immune signal was amplified using the Avidin-Biotin Complex (Thermo Scientific; Ultra-Sensitive $A B C$ Peroxidase Staining Kit, 32050) and developed with $0.5 \mathrm{mg} / \mathrm{mL}$ diaminobenzidine (Sigma, D5637) and $0.01 \%$ hydrogen peroxide. The sections were mounted on glass slides, dehydrated, cleared in xylene, and coverslipped with Depex (Serva, 18243). To avoid methodological differences, brain tissue from Wt, Mct8KO, Dio2KO and Mct8/Dio2KO animals of the same age were processed in parallel. Negative controls omitting the primary antibody were run in parallel and no staining was observed in control experiments with any of the antibodies used.

Quantification of the intensity of immunostaining for Pvalb and Nefh was performed in the motor and somatosensory cortex and, in the basal ganglia, in the caudate-putamen using 4 animals for each genotype at 3 months of age. For motor and somatosensory cortex, 3 representative sections were chosen per region, and 3 microphotographs were randomly captured in each section using a 40x oil-immersion objective. For studies in the caudateputamen, 3 representative sections were chosen, and 4 microphotographs were randomly captured in each section using a $20 x$ objective. All the images were captured with an Olympus DP70 digital camera joined to an Olympus BX51microscope, using the CAST stereological software package (Visiopharm, Hørsholm, Denmark, and Olympus España). Images were collected in TIFF format and transformed to 8-bit gray using the image 
analysis software ImageJ (Wayne Rasband, National Institutes of Health, USA). The median gray value of the pixels from the entire photograph was automatically assigned by ImageJ software. These data were corrected by the tissue background signal and transformed to percentage relative to mean value of the Wt animals (which is represented as $100 \%$ ).

For morphometric analysis of the thyroid gland four thyroid slices from each animal (4 Wt and 4 Mct8/Dio2KO) were used to study the size of the thyroid follicles by NIH Image J software. In each slice, we quantified the area of 50 follicles.

\section{Data analyses}

Data are expressed as mean \pm SE. Differences between means were obtained by one-way analysis of variance (ANOVA) and the Bonferroni's post hoc test to correct for multiple comparisons or by the Student's t-test to compare values between two groups using the GraphPad software (www.graphpad.com). Significant differences are represented as ${ }^{*} p<$ $0.05, * * p<0.01$ and $* * * p<0.001$.

In the balance beam test, the differences in the activity on the bar between Wt and Mct8/Dio2KO mice were calculated by $2 \times 2$ contingency tables and the Fisher's exact test.

The rotarod test was analyzed by two general linear models (one for 3-month-old and another for 6-month-old animals) using "latency to fall" as the dependent variable and, as independent variables, genotype (Wt, Mct8KO, Dio2KO and Mct8/Dio2KO) and day (first, second, third, fourth and fifth day of test) with the SPSS statistics 19 package. For comparison of values between $\mathrm{Wt}$ and Mct8/Dio2KO animals, Student's t-test was used and significant differences are represented as \#p $<0.05$, \#\#p $<0.01$ and \#\#\#p $<0.001$.

\section{Results}

Mct8/Dio2KO mice present abnormal TH levels/content in plasma and tissues and larger thyroid follicles

3 and 6-months-old Mct8/Dio2KO mice present peripheral TH alterations, showing high T3 (3-fold at 3 months of age and 1.5-fold at 6 months of age) and low T4 (nearly 2-fold at 3 months of age and 1.5-fold at 6 months of age) plasma levels in comparison to Wt mice. All 
these data are consistent with previous findings in 1 and 3-month-old Mct8/Dio2KO mice $(30,39)$, similarly to single Mct8KO animals and resembling the peripheral situation of MCT8-deficient patients (Figure 1A). Indeed, 3 and at 6 month-old Mct8KO mice present high T3 (2.7-fold) and low T4 (2-fold) plasma levels, as previously reported $(17,18,40)$. Dio2KO mice displayed unaltered T3 and high T4 (1.3-fold at both ages) plasma levels, as already described $(36,41)$. Although TSH levels were not assessed in the present work, they have been found to be elevated in Mct8KO, Dio2KO and Mct8/Dio2KO mice by others $(17,30,31,40)$.

Due to the deleterious effects that the peripheral hyperthyroidism causes on the muscle of MCT8-deficient patients, we measured TH content in the skeletal muscle. We found that 3 and 6-month-old Mct8KO mice present high T3 content in the skeletal muscle (2.5-fold at 3 months and 2-fold at 6 months of age in comparison to Wt) as previously reported in 3month-old mice $(42,43)$ and no alterations in T4 content in the skeletal muscle at 3 months of age as recently found (43). Interestingly, we observed that there is a 1.3-fold reduction in the skeletal muscle content of T4 in 6-month-old Mct8KO animals, indicating a change in the muscular TH content with age in comparison to $\mathrm{Wt}$ values. Dio2KO mice displayed high T4 content in the skeletal muscle $(1.3$-fold) at 3 months of age but T4 content was not altered in 6-month-old DiO2KO mice, consistent with our previous findings (36). Most importantly, double Mct8/Dio2KO mice presented high T3 content in the skeletal muscle (3-fold at 3 months of age and 2-fold at 6 months of age), no alterations in the T4 content at 3 months of age but, as observed in the single Mct8KO animals, decreased T4 content (1.7-fold) in the skeletal muscle of 6-month-old Mct8/Dio2KO mice in comparison to $\mathrm{Wt}$ animals, again indicating variations in the $\mathrm{TH}$ content of the skeletal muscle with age (Figure 1B).

In the cerebral cortex, 3- and 6-month-old single Mct8KO mice presented a 1.5 -fold reduction in the T3 content as previously found $(17,18)$ and no change in the content of T4. Dio2KO mice presented a 1.25-fold decrease in the cerebral cortex content of T3 at 3 months of age (although this decrease was not statistically significant), a 1.70-fold reduction in the T3 content at 6 months of age and a 1.5 -fold increase in the content of T4 in the cerebral cortex at both ages, consistent with previous findings $(36,41)$. Double 
Mct8/Dio2KO mice presented a strong decrease in the content of T3 in the cerebral cortex at both ages (2.25-fold at 3 months and over 3.5 -fold at 6 months of age) and no variations in the content of T4 (Figure 1C).

In the striatum, another brain region that contains the caudate-putamen and the globus pallidus, Mct8KO mice exhibited a decrease in the content of T3 at $3(1.75$-fold) and 6 months of age (2.25-fold) and a slight decrease in the content of T4 at 6 months of age that was not statistically significant. 3-month-old Dio2KO mice presented a 1.5-fold increase in the content of T4 in this region. Finally, double Mct8/Dio2KO displayed a severe decrease in the content of T3 in the striatum at 3 and at 6 months of age (13- and 18-fold, respectively) and no changes in the content of T4 (Figure 1D).

When we studied the morphology of the thyroid gland in 6-month-old Mct8/Dio2KO animals we found larger follicular areas (1.7-fold) in comparison to Wt animals (Figure 2), as previously described for several mice models lacking functional Mct8 protein expression $(30,40,44)$.

\section{Mct8/Dio2KO mice present pronounced motor skill impairments}

First, we evaluated the ability of Wt, Mct8KO, Dio2KO and double Mct8/Dio2KO mice to perform motor tasks exploring gait, coordination, balance and muscle strength. As age can be an influential factor in these tests, and taking into account that most patients are diagnosed late after birth, these studies were performed in young adult mice ( 3 months of age) and adult mice ( 6 months of age). We found no abnormalities in Mct8KO animals as previously reported (20), however, we found profound motor skill impairments in Mct8/Dio2KO mice.

The gait of the animals was studied by the footprint test. Mct8/Dio2KO exhibited an altered gait pattern in comparison to $\mathrm{Wt}$ animals with increased hindlimb stride width, and decreased forelimb and hindlimb stride length. Interestingly forelimb stride width was no different from Wt animals. These observations were similar at 3 and 6 months of age. Mct8KO animals exhibited gait parameters similar to Wt mice and Dio2KO presented decreased forelimb stride length only at 3 months of age (Figure 3). 
In order to further characterize the locomotor behavior of Mct8/Dio2KO, we studied their performance in the accelerating rotarod test. The ability of the animals to stay on the accelerating rod was tested for 5 consecutive days at 3 and 6 months of age. 3-month-old Mct8/Dio2KO animals tended to fall from the rotarod earlier than the mice with the other genotypes, but the latency to fall off the rod was only significantly decreased during the first day of the test. There were no differences in the locomotor performance of 3-monthold Wt, Mct8KO and Dio2KO mice. At 6 months of age Mct8/Dio2KO mice showed pronounced alterations in their performance in the rotarod test, as the latency to fall off the rod was much lower in Mct8/Dio2KO mice in comparison to $\mathrm{Wt}$ animals in every day of the test. At this age, neither Mct8KO nor Dio2KO animals showed any statistically significant differences in the performance in the rotarod test in comparison to $\mathrm{Wt}$ mice (Figure 4A). The alterations in rotarod performance observed in 6-month-old Mct8/Dio2KO animals in comparison to $\mathrm{Wt}$ are unlikely to be related to the low body weight of Mct8/Dio2KO animals, since 6 months old Mct8/Dio2KO mice have increased body weight in comparison to younger mice (e.g. 3-month-old), and their performance in the rotarod is much more impaired than at 3 months of age.

Equilibrium is not affected in Mct8/Dio2KO mice as can be seen from the balance beam test. The latency to fall off the beam was not different in Wt, Mct8KO, Dio2KO and Mct8/Dio2KO animals at 3 and 6 months of age neither in the first or the second trial (Figure 4B). The activity on the bar was not different between Wt and Mct8/Dio2KO animals. At 3 months of age 70\% and 50\% of Wt and Mct8/Dio2KO animals, respectively, reached the end of the bar on the first trial $(p=0.6499)$ and, in the second trial, $90 \%$ of the Wt mice and $60 \%$ of Mct8/Dio2KO animals arrived to the end of the bar $(p=0.3034$.). At 6 months of age, on the first trial $90 \%$ and 55\% of Wt and Mct8/Dio2KO animals reached the end of the bar $(p=0.1409)$ and, in the second trial, $100 \%$ of the Wt animals and $66 \%$ of Mct8/Dio2KO animals walked to the end of the bar $(p=0.0867)$.

Finally, we explored muscle strength in the four limb hanging wire test. Mct8/Dio2KO mice displayed severe alterations in muscle strength in comparison to their matched age control Wt animals. While Wt and Mct8KO animals were able hold from the grid for the entire test period (120 seconds), the mean holding latency value was 28.70 seconds for 3 -month-old 
Mct8/Dio2KO mice and 13.63 seconds for 6-month-old Mct8/Dio2KO. Grip strength was also severely impaired in Dio2KO mice with a mean holding latency value of 64.19 seconds for 3-month-old mice and 14.43 seconds for 6-month-old animals (Figure 4C).

\section{Mct8/Dio2KO mice present brain alterations at the histological level}

The only study that has explored the neuropathology of the syndrome by analyzing brain tissue sections from MCT8-deficient subjects published so far, revealed serious alterations in brains of a 30th gestational week male fetus and an 11-year-old boy. Among these alterations there was a loss of parvalbumin expression and impaired axonal maturation (19).

To assess whether Mct8/Dio2KO mice replicate some of these alterations, we extensively characterized the expression of Parvalbumin (Pvalb) and Neurofilament heavy chain (Nefh) in brain slices of Wt, Mct8KO, Dio2KO and Mct8/Dio2KO mice at 3 and 6 months of age. We focused the analysis on the cerebral cortex (motor and somatosensory cortex) and the basal ganglia (caudate-putamen and substantia nigra) due to the significant impairments observed in these regions.

As shown in Figure 5, at 3 months of age the expression of the calcium-binding protein Pvalb was abnormal in the cerebral cortex of Mct8/Dio2KO animals, which displayed a severe decrease in the expression of this protein in the motor and the somatosensory cortex in comparison to $\mathrm{Wt}$ animals $(55.6 \% \pm 5.93 \%, p=0.0049$ and $56.4 \% \pm 0.80 \%, p=$ 0.0002 , respectively, as compared to $100 \%$ for the $\mathrm{Wt}$ group). The expression of Pvalb was also decreased in these regions in the Mct8KO, although to a much lesser extent compared to Mct8/Dio2KO animals $(65.4 \% \pm 6.09 \%, p=0.0084$ and $75.1 \% \pm 2.37 \%, p=0.0013)$. Dio2KO mice also showed a significant reduction at the motor cortex $(70.5 \% \pm 2.54 \%, p=$ $0.0059)$ and especially at the somatosensory cortex $(54.6 \% \pm 3.78 \%, p=0.0001)$. In the basal ganglia, the immunostaining of Pvalb was strongly decreased in the caudateputamen and the substantia nigra of Mct8/Dio2KO mice when compared to Wt animals (59.4\% $\pm 6.53 \%, p=0.0015$ for caudate-putamen). The expression of this protein was also reduced in the basal ganglia of Mct8KO and Dio2KO animals, although this reduction was 
not as strong as in Mct8/Dio2KO mice $(76.8 \% \pm 4.35 \%, p=0.0129$ and $75.2 \% \pm 3.28 \%, p=$ 0.0041 , respectively).

As shown in Figure 6, at 3 months of age there was a distinctive staining pattern for Nefh in Mct8/Dio2KO mice. The expression of this protein was markedly reduced in the cerebral cortex of Mct8/Dio2KO mice, especially at the somatosensory cortex $(63.4 \% \pm 6.47 \%, p=$ 0.0090 and $51.6 \% \pm 3.90 \%, p<0.0001$, for motor and somatosensory cortex, respectively). At the basal ganglia there was also a reduction in the intensity of expression of Nefh in the caudate-putamen and the substantia nigra in Mct8/Dio2KO animals in comparison to $\mathrm{Wt}$ (77.7\% $\pm 3.99 \%, p=0.0276$ for caudate-putamen). In Mct8KO and Dio2KO mice the expression of Nefh in the cerebral cortex was also decreased, although not as severely as in double Mct8/Dio2KO mice $(78.6 \% \pm 5.71 \%, p=0.0454$ and $78.9 \% \pm 5.93 \%, p=0.0216$ for Mct8KO and $78.5 \% \pm 4.59 \%, p=0.0278$ and $81.7 \% \pm 2.81 \%, p=0.0062$ for Dio2KO mice). However, the expression of Nefh in basal ganglia was very similar to control Wt animals $(84.2 \% \pm 7.20 \%, p=0.1554$ for Mct8KO and $92.8 \% \pm 3.23 \%, p=0.3664$ for Dio2KO animals in the caudate-putamen).

At 6 months of age, the immunostaining pattern for Pvalb and Nefh was very similar to the one observed in 3-month-old mice. In general, there was a strong decrease in the expression of these two proteins in the double Mct8/Dio2KO mice in comparison to $\mathrm{Wt}$ mice in all studied regions, and this decrease was much less pronounced in the Mct8KO or Dio2KO mice (data not shown).

\section{Discussion}

Due to the severe alterations that arise from mutations in the TH transporter MCT8, much effort has been put into understanding the causes that underlie such alterations and into developing successful therapeutic approaches. As data available from humans is limited $(45,46)$, the generation of appropriate models and instruments is essential in order to achieve these goals. The lack of the perfect model is hindering our understanding of MCT8 deficiency; therefore, the use of a comparative approach combining several models will be the best option to tackle this problem. 
Regarding mouse models, single Mct8KO mice are only a partial model of the disease as they do not reproduce the neurological alterations present in humans. Nevertheless, this model has provided much of the current knowledge regarding MCT8 deficiency. To begin with, Mct8KO mice have been useful to prove that despite having high serum T3 concentrations, there is a state of brain hypothyroidism with reduced T3 content $(17,18)$, and alterations in the expression of some T3-dependent genes (21). Moreover, thanks to elegant studies using Mct8KO mice, it was first suggested that the pathogenesis associated with MCT8 deficiency arises from an impaired T3 transport across the BBB (14). The double Mct8/Oatp1c1KO mouse seems to be a better model for the AHDS as it presents peripheral hyperthyroidism and brain alterations compatible with brain hypothyroidism. However, the fact that Oatp1c1 transports other molecules (28) and that OATP1C1deficiency in humans has been associated with neurological alterations (29), offers some limitations to consider the Mct8/Oatp1c1KO mouse as the ultimate model for the AHDS and highlights the need for alternative and additional models that support and complement each other. In this work we have characterized the Mct8/Dio2KO mouse as an alternative mouse model for the AHDS. We have found that young adult and adult Mct8/Dio2KO animals replicate the situation in MCT8-deficient patients with peripheral hyperthyroidism with increased plasma T3 levels and a state of brain hypothyroidism with decreased T3 content. In addition, they also present brain alterations at a histological level and display motor skill impairments compatible with the psychomotor abnormalities in MCT8-deficient patients. This model however, also presents certain limitations as it is deprived of Dio2, when patients present increased Dio2 activity in the brain, and does not fully replicate the low T4 content in the brain of MCT8-deficient patients (19).

The three Mct8-deficient mouse models (Mct8KO, Mct8/Oatp1c1KO and Mct8/Dio2KO), like MCT8-deficient patients, present increased T3 plasma levels that lead to thyrotoxicosis due to an excess of T3 in peripheral tissues. Indeed, studies in 3-month-old Mct8KO mice have demonstrated that these mice have hypermetabolism with increased total energy expenditure (42) and that, despite lacking Mct8, there is a hyperthyroid state of the kidneys (47) and the skeletal muscle (42). Double Mct8/Oatp1c1KO mice have been recently found to also present a thyrotoxic state in skeletal muscle (43), and we now 
provide evidence that Mct8/Dio2KO mice also exhibit a hyperthyroid state of the skeletal muscle at 3 and 6 months of age. Regarding T4 content in the skeletal muscle, we have found that 3-month-old Mct8KO and Mct8/Dio2KO present normal T4 values despite low T4 circulating levels consistent with previous data in Mct8KO mice (42) and Mct8/Oatp1c1KO mice (43) of approximately the same age. Intriguingly, T4 content was low in 6-month-old Mct8KO and Mct8/Dio2KO mice suggesting that there are variations in the content of THs with age. These findings are relevant as the skeletal muscle is an important TH target (48) and the Mct8 transporter seems to play an important role in muscle regeneration (43). Analysis of these three mouse models will provide further evidence regarding the peripheral effects of MCT8 deficiency at different ages.

Another important finding of the present work is that there seems to be selective sensitivity to Mct8-deficiency across brain regions, as previously suggested (49). In the cerebral cortex, we have found a decrease of T3 in 3 and 6-month-old Mct8KO animals to approximately $60 \%$ of the content in Wt animals, while in the striatum T3 content decreased to $55 \%$ and $40 \%$ of the $\mathrm{Wt}$ values at 3 and 6 months of age, respectively. This indicates that the striatum is more sensitive to Mct8-deficiency than the cerebral cortex. This finding was more robust in double Mct8/Dio2KO animals. In the cerebral cortex there was a decline in the content of T3 to approximately $40 \%$ and $25 \%$ of the $\mathrm{Wt}$ values at 3 and 6 months of age, respectively, and in the striatum there was a decrease to $8 \%$ and $5 \%$ of the Wt content at 3 and 6 months of age respectively. The striatum includes the caudateputamen and the globus pallidus, which are the main components of the basal ganglia, responsible mainly for motor control and also for motor learning, executive functions and behaviors and emotions (50). MCT8-deficient patients have been shown to have important lesions in the putamen by MRI studies (11), so our results could have important implications for the understanding of the syndrome and its treatment. Due to the poor control movement of MCT8-deficient patients, these findings could point to the basal ganglia as an important target for therapeutic treatments.

To continue with the brain, these three Mct8-deficient mouse models present a state of brain hypothyroidism with decreased T3 content. Cerebral T3 content in Mct8KO and Mct8/Dio2KO mice has been discussed above and double Mct8/Oatp1c1KO mice have 
been shown to have a decrease of T3 to approximately $10 \%$ of the levels in Wt animals in the forebrain at P21. The state of brain hypothyroidism leads to alterations at the histological level to different extent in each model. We have found very mild alterations with a slight reduction in the expression of Pvalb in Mct8KO animals as previously shown (20). In this study, the authors characterized the immunohistochemical expression of Pvalb in Mct8KO mice for the first time and they concluded that there were no alterations in the number or distribution of Pvalb-positive interneurons.

Like in Mct8/Oatp1c1KO mice (27), we have detected important alterations in the expression of Pvalb in the brain of Mct8/Dio2KO mice at 3 and 6 months of age. There was reduced expression of Pvalb in the motor and the somatosensory cortex and in the basal ganglia. This is consistent with the reduced T3 content found in the cerebral cortex and the striatum of Mct8/Dio2KO mice and with previous studies that have detected alterations in Pvalb immunoreactivity under TH insufficiency conditions (51-53). Most importantly, this finding is in agreement with observations in the brain of a MCT8-deficient subject where PVALB expression was not detected in the cerebral cortex (19). In this same study, the expression of neurofilaments immunoreactivity was remarkably reduced or even absent in the cerebral cortex of a MCT8-deficient subject. In the present work we have found reduced immunoreactivity of Nefh in the cerebral cortex, the caudate-putamen and the substantia nigra of Mct8/Dio2KO mice. As in the case of Pvalb, this is in agreement with the reduced T3 content detected in the cerebral cortex and the striatum of Mct8/Dio2KO mice and with previous studies describing alterations in neurofilament immunoreactivity under TH deficiency (54-56). These findings might have important implications as the reduction in Pvalb immunoreactivity suggests that there are profound alterations in the inhibitory interneurons that mediate feedforward inhibition in thalamocortical, interlaminar and interareal circuits (57) and the decrease in Nefh immunostaining indicates that there are important neuronal maturation impairments (58).

We have also found important motor skill impairments in Mct8/Dio2KO mice. These alterations have also been described in Mct8/Oatp1c1KO animals and include variations in global gait pattern, reduced grip strength and decreased motor coordination. Interestingly, while Mct8/Oap1c1KO mice exhibit abnormalities in the rotarod performance in every day 
of the test at 3 months of age, Mct8/Dio2KO showed an altered performance pattern that was only statistically significant on the first day of training at this age. However, rotarod performance of 6-month-old Mct8/Dio2KO mice showed severe impairments in every day of test. This raises the question about the underlying differences between developmental stages and between the mouse genotypes that may explain the differential rotarod performance.

Studies in MCT8-deficient subjects show that patients present important brain alterations already from prenatal stages (19). It is therefore indispensable to study these animal models in perinatal stages in order to unravel the mechanisms underlying MCT8-deficient brain development and to design appropriate therapeutic strategies. Mct8/Dio2KO mice have decreased expression of some T3 dependent genes at postnatal day 3 in the brain (59) but further analysis should be performed. This is especially important as the role of MCT8 in the perinatal period is still unclear. Single Mct8KO mice present with cerebral hyperthyroidism during the perinatal period $(60,61)$. Moreover, Mct8-deficient zebrafish present neurological and behavioral deficiencies very early in development without changes in the expression of the T3-target genes KIf9 and Nrgna, suggesting that MCT8 might have a $\mathrm{TH}$-independent role that induces neurological deficiencies in the perinatal period (62). The use of the current available mouse models and additional models including human patient-derived induced pluripotent stem cells (16) and non-mammalian vertebrates like zebrafish (63), chicken (64) or even Xenopus (65) will be necessary to explore this and other aspects of the syndrome and to provide additional insights into the human disease.

In summary, this study expands the phenotypic characterization of Mct8/Dio2KO mice as an additional and alternative model for human MCT8 deficiency. 3- and 6-month-old Mct8/Dio2KO mice display abnormal circulating TH levels with low T4 and high T3 resembling the human condition, a state of brain hypothyroidism with reduced T3 content varying across brain regions, alterations at the histological level and locomotor impairments. Importantly, the observed alterations persist and even aggravate with age. In addition, this mouse model has already been reported to present changes in the expression of T3-target genes in the brain of juvenile (21) and perinatal (59) animals. 
Indeed, Mct8/Dio2KO mice have already been used to test possible therapeutic interventions for MCT8 deficiency (39), but the findings presented here offer additional markers to expand the markers allowing to assess the impact of therapeutic interventions.

Further characterization of this and other models at different developmental stages will provide further insights into the molecular underpinnings of developmental brain disorders under $\mathrm{TH}$ deficiency conditions and will offer additional tools to develop therapeutic strategies to prevent and/or restore brain damage in MCT8-deficient patients.

\section{Acknowledgements}

This work was supported by Grants from the Spanish Plan Nacional de I+D+i (grant number SAF2017-86342-R to A.GF), the Sherman Foundation (OTR02211 to A.GF and S.BL) and the Center for Biomedical Research on Rare Diseases (Ciberer), Instituto de Salud Carlos III, Madrid, Spain. The cost of this publication has been paid in part by FEDER funds. We thank Dr Maria Jesus Obregon for her valuable assistance with thyroid hormone determinations, María Camino de Lucas for animal care and Dr Juan Bernal for critical reading of the manuscript and helpful discussions. We acknowledge $\mathrm{Dr}$ Valerie Anne Galton and $\mathrm{Dr}$ Samuel Refetoff for the generous gift of the Dio2KO and Mct8KO mice, respectively.

\section{Disclosure Statement}

The authors declare that no competing interests exist.

\section{Corresponding authors}

Ana Guadaño-Ferraz (PhD).

Address: Department of Endocrine and Nervous System Pathophysiology, Instituto de Investigaciones Biomédicas Alberto Sols, Consejo Superior de Investigaciones CientíficasUniversidad Autónoma de Madrid, Arturo Duperier 4, E-28029 Madrid, Spain

Telephone: +34915854494

Email: aguadano@iib.uam.es 
Soledad Bárez-López (PhD).

Address: Department of Endocrine and Nervous System Pathophysiology, Instituto de Investigaciones Biomédicas Alberto Sols, Consejo Superior de Investigaciones CientíficasUniversidad Autónoma de Madrid, Arturo Duperier 4, E-28029 Madrid, Spain Telephone: +34915854465

Email: soledad.barez@gmail.es 


\section{References}

1. Allan W, Herndon C, Dudley F 1944 Some examples of the inheritance of mental deficiency: apparently sex-linked idiocy and microencephaly. Am J Ment Defic 48:325-334.

2. Dumitrescu AM, Liao XH, Best TB, Brockmann K, Refetoff S 2004 A novel syndrome combining thyroid and neurological abnormalities is associated with mutations in a monocarboxylate transporter gene. Am J Hum Genet 74:168-175.

3. Friesema EC, Grueters A, Biebermann $H$, Krude $H$, von Moers A, Reeser $M$, Barrett TG, Mancilla EE, Svensson J, Kester MH, Kuiper GG, Balkassmi S, Uitterlinden AG, Koehrle J, Rodien P, Halestrap AP, Visser TJ 2004 Association between mutations in a thyroid hormone transporter and severe X-linked psychomotor retardation. Lancet 364:1435-1437.

4. Holden KR, Zuniga OF, May MM, Su H, Molinero MR, Rogers RC, Schwartz CE 2005 X-linked MCT8 gene mutations: characterization of the pediatric neurologic phenotype. J Child Neurol 20:852-857.

5. Schwartz CE, May MM, Carpenter NJ, Rogers RC, Martin J, Bialer MG, Ward J, Sanabria J, Marsa S, Lewis JA, Echeverri R, Lubs HA, Voeller K, Simensen RJ, Stevenson RE 2005 Allan-Herndon-Dudley syndrome and the monocarboxylate transporter 8 (MCT8) gene. Am J Hum Genet 77:41-53.

6. Biebermann H, Ambrugger P, Tarnow P, von Moers A, Schweizer U, Grueters A 2005 Extended clinical phenotype, endocrine investigations and functional studies of a loss-of-function mutation A150V in the thyroid hormone specific transporter MCT8. Eur J Endocrinol 153:359-366.

7. Schwartz CE, Stevenson RE 2007 The MCT8 thyroid hormone transporter and AllanHerndon-Dudley syndrome. Best Pract Res Clin Endocrinol Metab 21:307-321.

8. Papadimitriou A, Dumitrescu AM, Papavasiliou A, Fretzayas A, Nicolaidou P, Refetoff S 2008 A novel monocarboxylate transporter 8 gene mutation as a cause of severe neonatal hypotonia and developmental delay. Pediatrics 121:e199-202. 
9. Boccone L, Dessi V, Meloni A, Loudianos G 2013 Allan-Herndon-Dudley syndrome (AHDS) in two consecutive generations caused by a missense MCT8 gene mutation. Phenotypic variability with the presence of normal serum T3 levels. Eur J Med Genet 56:207-210.

10. Herzovich V, Vaiani E, Marino R, Dratler G, Lazzati JM, Tilitzky S, Ramirez P, lorcansky S, Rivarola MA, Belgorosky A 2007 Unexpected peripheral markers of thyroid function in a patient with a novel mutation of the MCT8 thyroid hormone transporter gene. Horm Res 67:1-6.

11. Kakinuma $\mathrm{H}$, Itoh $\mathrm{M}$, Takahashi $\mathrm{H} 2005$ A novel mutation in the monocarboxylate transporter 8 gene in a boy with putamen lesions and low free T4 levels in cerebrospinal fluid. J Pediatr 147:552-554.

12. Swiston CJ, Nash DL 2018 Intermittent Esotropia in 4 Patients With Allan-HerndonDudley Syndrome. J Child Neurol 33:525-527.

13. Matheus MG, Lehman RK, Bonilha L, Holden KR 2015 Redefining the Pediatric Phenotype of X-Linked Monocarboxylate Transporter 8 (MCT8) Deficiency: Implications for Diagnosis and Therapies. J Child Neurol 30:1664-1668.

14. Ceballos A, Belinchón MM, Sanchez-Mendoza E, Grijota-Martínez C, Dumitrescu AM, Refetoff S, Morte B, Bernal J 2009 Importance of monocarboxylate transporter 8 for the blood-brain barrier-dependent availability of 3,5,3'-triiodo-L-thyronine. Endocrinology 150:2491-2496.

15. Iwayama H, Liao XH, Braun L, Bárez-López S, Kaspar B, Weiss RE, Dumitrescu AM, Guadaño-Ferraz A, Refetoff S 2016 Adeno Associated Virus 9-Based Gene Therapy Delivers a Functional Monocarboxylate Transporter 8, Improving Thyroid Hormone Availability to the Brain of Mct8-Deficient Mice. Thyroid 26:1311-1319.

16. Vatine GD, Al-Ahmad A, Barriga BK, Svendsen S, Salim A, Garcia L, Garcia VJ, Ho R, Yucer N, Qian T, Lim RG, Wu J, Thompson LM, Spivia WR, Chen Z, Van Eyk J, Palecek SP, Refetoff S, Shusta EV, Svendsen CN 2017 Modeling Psychomotor Retardation using iPSCs from MCT8-Deficient Patients Indicates a Prominent Role for the BloodBrain Barrier. Cell Stem Cell 20:831-843 e835. 
17. Dumitrescu AM, Liao XH, Weiss RE, Millen K, Refetoff S 2006 Tissue-specific thyroid hormone deprivation and excess in monocarboxylate transporter (mct) 8-deficient mice. Endocrinology 147:4036-4043.

18. Trajkovic M, Visser TJ, Mittag J, Horn S, Lukas J, Darras VM, Raivich G, Bauer K, Heuer H 2007 Abnormal thyroid hormone metabolism in mice lacking the monocarboxylate transporter 8. J Clin Invest 117:627-635.

19. López-Espíndola D, Morales-Bastos C, Grijota-Martínez C, Liao XH, Lev D, Sugo E, Verge CF, Refetoff S, Bernal J, Guadaño-Ferraz A 2014 Mutations of the thyroid hormone transporter MCT8 cause prenatal brain damage and persistent hypomyelination. J Clin Endocrinol Metab 99:E2799-2804.

20. Wirth EK, Roth S, Blechschmidt C, Holter SM, Becker L, Racz I, Zimmer A, Klopstock T, Gailus-Durner V, Fuchs H, Wurst W, Naumann T, Brauer A, de Angelis MH, Kohrle J, Gruters A, Schweizer U 2009 Neuronal 3',3,5-triiodothyronine (T3) uptake and behavioral phenotype of mice deficient in Mct8, the neuronal T3 transporter mutated in Allan-Herndon-Dudley syndrome. J Neurosci 29:9439-9449.

21. Morte B, Ceballos A, Díez D, Grijota-Martínez C, Dumitrescu AM, Di Cosmo C, Galton VA, Refetoff S, Bernal J 2010 Thyroid hormone-regulated mouse cerebral cortex genes are differentially dependent on the source of the hormone: a study in monocarboxylate transporter-8- and deiodinase-2-deficient mice. Endocrinology 151:2381-2387.

22. Pizzagalli F, Hagenbuch B, Stieger B, Klenk U, Folkers G, Meier PJ 2002 Identification of a novel human organic anion transporting polypeptide as a high affinity thyroxine transporter. Mol Endocrinol 16:2283-2296.

23. Sugiyama $D$, Kusuhara $H$, Taniguchi $H$, Ishikawa $S$, Nozaki $Y$, Aburatani $H$, Sugiyama $Y$ 2003 Functional characterization of rat brain-specific organic anion transporter (Oatp14) at the blood-brain barrier: high affinity transporter for thyroxine. J Biol Chem 278:43489-43495.

24. Zhang Y, Chen K, Sloan SA, Bennett ML, Scholze AR, O'Keeffe S, Phatnani HP, Guarnieri P, Caneda C, Ruderisch N, Deng S, Liddelow SA, Zhang C, Daneman R, Maniatis T, Barres BA, Wu JQ 2014 An RNA-sequencing transcriptome and splicing database of glia, neurons, and vascular cells of the cerebral cortex. J Neurosci 34:11929-11947. 
25. Ito K, Uchida Y, Ohtsuki S, Aizawa S, Kawakami H, Katsukura Y, Kamiie J, Terasaki T 2011 Quantitative membrane protein expression at the blood-brain barrier of adult and younger cynomolgus monkeys. J Pharm Sci 100:3939-3950.

26. Zhang Y, Sloan SA, Clarke LE, Caneda C, Plaza CA, Blumenthal PD, Vogel H, Steinberg GK, Edwards MS, Li G, Duncan JA, 3rd, Cheshier SH, Shuer LM, Chang EF, Grant GA, Gephart MG, Barres BA 2016 Purification and Characterization of Progenitor and Mature Human Astrocytes Reveals Transcriptional and Functional Differences with Mouse. Neuron 89:37-53.

27. Mayerl S, Muller J, Bauer R, Richert S, Kassmann CM, Darras VM, Buder K, Boelen A, Visser TJ, Heuer H 2014 Transporters MCT8 and OATP1C1 maintain murine brain thyroid hormone homeostasis. J Clin Invest 124:1987-1999.

28. Westholm DE, Salo DR, Viken KJ, Rumbley JN, Anderson GW 2009 The blood-brain barrier thyroxine transporter organic anion-transporting polypeptide $1 \mathrm{c} 1$ displays atypical transport kinetics. Endocrinology 150:5153-5162.

29. Stromme P, Groeneweg S, Lima de Souza EC, Zevenbergen C, Torgersbraten A, Holmgren A, Gurcan E, Meima M, Peeters R, Visser WE, Honeren Johansson L, Babovic A, Zetterberg H, Heuer H, Frengen E, Misceo D, Visser TJ 2018 Mutated thyroid hormone transporter OATP1C1 associates with severe brain hypometabolism and juvenile neurodegeneration. Thyroid.

30. Liao XH, Di Cosmo C, Dumitrescu AM, Hernandez A, Van Sande J, St Germain DL, Weiss RE, Galton VA, Refetoff S 2011 Distinct roles of deiodinases on the phenotype of Mct8 defect: a comparison of eight different mouse genotypes. Endocrinology 152:1180-1191.

31. Schneider MJ, Fiering SN, Pallud SE, Parlow AF, St Germain DL, Galton VA 2001 Targeted disruption of the type 2 selenodeiodinase gene (DIO2) results in a phenotype of pituitary resistance to T4. Mol Endocrinol 15:2137-2148.

32. Weeke J, Orskov H 1973 Synthesis of 125I monolabelled 3, 5, 3'-triiodothyronine and thyroxine of maximum specific activity for radioimmunoassay. Scand J Clin Lab Invest 32:357-360. 
33. Obregon MJ, Morreale de Escobar G, Escobar del Rey F 1978 Concentrations of triiodo-L-thyronine in the plasma and tissues of normal rats, as determined by radioimmunoassay: comparison with results obtained by an isotopic equilibrium technique. Endocrinology 103:2145-2153.

34. Morreale de Escobar G, Pastor R, Obregon MJ, Escobar del Rey F 1985 Effects of maternal hypothyroidism on the weight and thyroid hormone content of rat embryonic tissues, before and after onset of fetal thyroid function. Endocrinology 117:1890-1900.

35. Ruiz de Oña C, Obregon MJ, Escobar del Rey F, Morreale de Escobar G 1988 Developmental changes in rat brain 5'-deiodinase and thyroid hormones during the fetal period: the effects of fetal hypothyroidism and maternal thyroid hormones. Pediatr Res 24:588-594.

36. Bárez-López S, Bosch-García D, Gómez-Andrés D, Pulido-Valdeolivas I, MonteroPedrazuela A, Obregon MJ, Guadaño-Ferraz A 2014 Abnormal motor phenotype at adult stages in mice lacking type 2 deiodinase. PLoS One 9:e103857.

37. Crawley JN 2000 What's Wrong With My Mouse? Behavioral Phenotyping of Transgenic and Knockout Mice. Wiley-Liss, New York.

38. Arque G, de Lagran MM, Arbones ML, Dierssen M 2009 Age-associated motor and visuo-spatial learning phenotype in Dyrk1A heterozygous mutant mice. Neurobiol Dis 36:312-319.

39. Bárez-López S, Hartley MD, Grijota-Martínez C, Scanlan TS, Guadaño-Ferraz A 2018 Sobetirome and its Amide Prodrug Sob-AM2 Exert Thyromimetic Actions in Mct8Deficient Brain. Thyroid 28:1211-1220.

40. Wirth EK, Sheu SY, Chiu-Ugalde J, Sapin R, Klein MO, Mossbrugger I, QuintanillaMartinez L, de Angelis MH, Krude H, Riebel T, Rothe K, Kohrle J, Schmid KW, Schweizer U, Gruters A 2011 Monocarboxylate transporter 8 deficiency: altered thyroid morphology and persistent high triiodothyronine/thyroxine ratio after thyroidectomy. Eur J Endocrinol 165:555-561.

41. Galton VA, Wood ET, St Germain EA, Withrow CA, Aldrich G, St Germain GM, Clark AS, St Germain DL 2007 Thyroid hormone homeostasis and action in the type 2 deiodinase-deficient rodent brain during development. Endocrinology 148:3080-3088. 
42. Di Cosmo C, Liao XH, Ye H, Ferrara AM, Weiss RE, Refetoff S, Dumitrescu AM 2013 Mct8-deficient mice have increased energy expenditure and reduced fat mass that is abrogated by normalization of serum T3 levels. Endocrinology 154:4885-4895.

43. Mayerl S, Schmidt M, Doycheva D, Darras VM, Huttner SS, Boelen A, Visser TJ, Kaether C, Heuer H, von Maltzahn J 2018 Thyroid Hormone Transporters MCT8 and OATP1C1 Control Skeletal Muscle Regeneration. Stem Cell Reports 10:1959-1974.

44. Di Cosmo C, Liao XH, Dumitrescu AM, Philp NJ, Weiss RE, Refetoff S 2010 Mice deficient in MCT8 reveal a mechanism regulating thyroid hormone secretion. J Clin Invest 120:3377-3388.

45. Vancamp P, Darras VM 2018 From zebrafish to human: A comparative approach to elucidate the role of the thyroid hormone transporter MCT8 during brain development. Gen Comp Endocrinol 265:219-229.

46. Bernal J, Guadaño-Ferraz A, Morte B 2015 Thyroid hormone transporters--functions and clinical implications. Nat Rev Endocrinol 11:406-417.

47. Trajkovic-Arsic M, Visser TJ, Darras VM, Friesema EC, Schlott B, Mittag J, Bauer K, Heuer H 2010 Consequences of monocarboxylate transporter 8 deficiency for renal transport and metabolism of thyroid hormones in mice. Endocrinology 151:802809.

48. Salvatore D, Simonides WS, Dentice M, Zavacki AM, Larsen PR 2014 Thyroid hormones and skeletal muscle--new insights and potential implications. Nat Rev Endocrinol 10:206-214.

49. !!! INVALID CITATION !!! Wirth, Roth, Blechschmidt, Holter, Becker, Racz, Zimmer, Klopstock, Gailus-Durner, Fuchs, Wurst, Naumann, Brauer, de Angelis, Kohrle, Gruters, Schweizer (20).

50. Lanciego JL, Luquin N, Obeso JA 2012 Functional neuroanatomy of the basal ganglia. Cold Spring Harb Perspect Med 2:a009621.

51. Berbel P, Marco P, Cerezo JR, DeFelipe J 1996 Distribution of parvalbumin immunoreactivity in the neocortex of hypothyroid adult rats. Neurosci Lett 204:6568. 
52. Gilbert ME, Sui L, Walker MJ, Anderson W, Thomas S, Smoller SN, Schon JP, Phani S, Goodman JH 2007 Thyroid hormone insufficiency during brain development reduces parvalbumin immunoreactivity and inhibitory function in the hippocampus. Endocrinology 148:92-102.

53. Harder L, Dudazy-Gralla S, Muller-Fielitz H, Hjerling Leffler J, Vennstrom B, Heuer H, Mittag J 2018 Maternal thyroid hormone is required for parvalbumin neurone development in the anterior hypothalamic area. J Neuroendocrinol 30:e12573.

54. Ghosh S, Rahaman SO, Sarkar PK 1999 Regulation of neurofilament gene expression by thyroid hormone in the developing rat brain. Neuroreport 10:2361-2365.

55. Gravel C, Hawkes R 1987 Thyroid hormone modulates the expression of a neurofilament antigen in the cerebellar cortex: premature induction and overexpression by basket cells in hyperthyroidism and a critical period for the correction of hypothyroidism. Brain Res 422:327-335.

56. Morte B, Díez D, Ausó E, Belinchón MM, Gil-Ibáñez P, Grijota-Martínez C, Navarro D, Morreale de Escobar G, Berbel P, Bernal J 2010 Thyroid hormone regulation of gene expression in the developing rat fetal cerebral cortex: prominent role of the Ca2+/calmodulin-dependent protein kinase IV pathway. Endocrinology 151:810820.

57. Burkhalter A 2008 Many specialists for suppressing cortical excitation. Front Neurosci 2:155-167.

58. Sarnat HB 2013 Clinical neuropathology practice guide 5-2013: markers of neuronal maturation. Clin Neuropathol 32:340-369.

59. Bárez-López S, Obregon MJ, Bernal J, Guadaño-Ferraz A 2018 Thyroid Hormone Economy in the Perinatal Mouse Brain: Implications for Cerebral Cortex Development. Cereb Cortex 28:1783-1793.

60. Ferrara AM, Liao XH, Gil-Ibáñez P, Marcinkowski T, Bernal J, Weiss RE, Dumitrescu AM, Refetoff S 2013 Changes in thyroid status during perinatal development of MCT8-deficient male mice. Endocrinology 154:2533-2541.

61. Núñez $B$, Martínez de Mena R, Obregon MJ, Font-Llitjos $M$, Nunes $V$, Palacín $M$, Dumitrescu AM, Morte B, Bernal J 2014 Cerebral cortex hyperthyroidism of newborn mct8-deficient mice transiently suppressed by lat2 inactivation. PLoS One 9:e96915. 
62. Zada D, Tovin A, Lerer-Goldshtein T, Vatine GD, Appelbaum L 2014 Altered behavioral performance and live imaging of circuit-specific neural deficiencies in a zebrafish model for psychomotor retardation. PLoS Genet 10:e1004615.

63. Vatine GD, Zada D, Lerer-Goldshtein T, Tovin A, Malkinson G, Yaniv K, Appelbaum L 2013 Zebrafish as a model for monocarboxyl transporter 8-deficiency. J Biol Chem 288:169-180.

64. Delbaere J, Vancamp P, Van Herck SL, Bourgeois NM, Green MJ, Wingate RJ, Darras VM 2017 MCT8 deficiency in Purkinje cells disrupts embryonic chicken cerebellar development. J Endocrinol 232:259-272.

65. Mughal BB, Leemans M, Lima de Souza EC, le Mevel S, Spirhanzlova P, Visser TJ, Fini JB, Demeneix BA 2017 Functional Characterization of Xenopus Thyroid Hormone Transporters mct8 and oatp1c1. Endocrinology 158:2694-2705. 

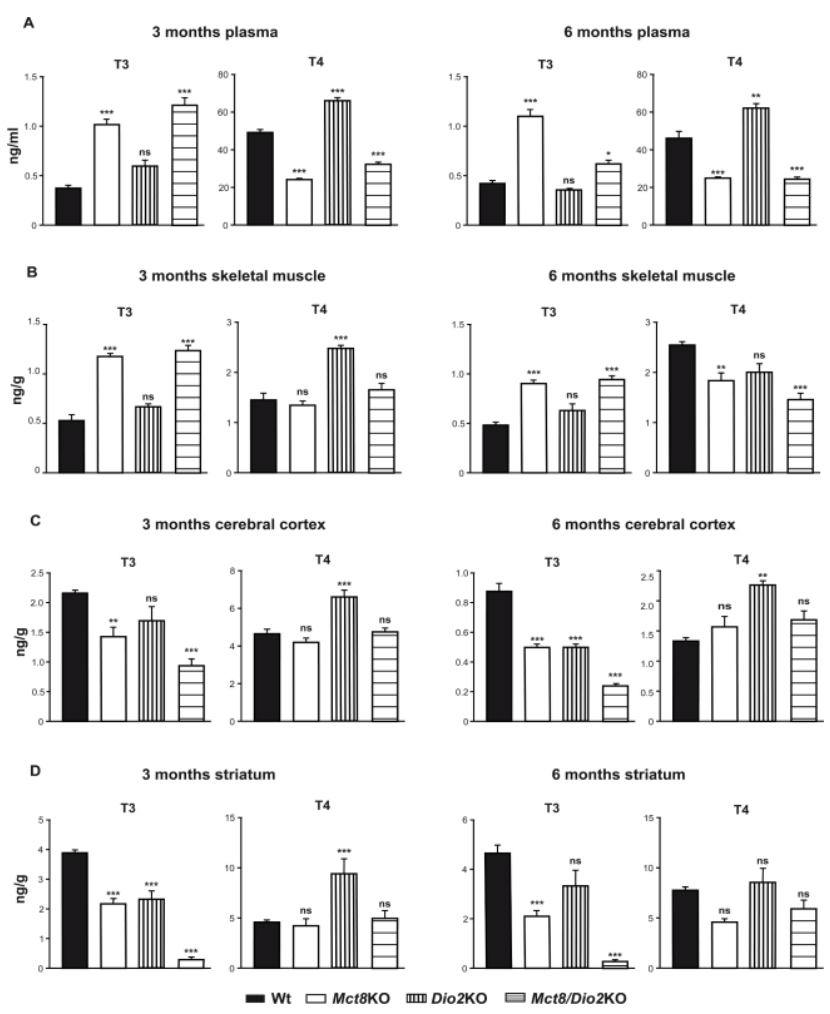

Figure 1. Thyroid hormone levels in plasma and tissues. (A) Triiodothyronine (T3) and Thyroxine (T4) plasma levels, (B) skeletal muscle content, (C) cerebral cortex content and (D) striatum content in wild-type $(\mathrm{Wt} ; \mathrm{n}=9)$, mice lacking monocarboxylate transporter 8 (Mct8KO; $n=9$ ), mice lacking deiodinase type 2 (Dio2KO; $n=7$ ) and Mct8/Dio2KO $(n=10)$ mice at 3 months of age and in Wt $(n=10), \operatorname{Mct8KO}(n=8), \operatorname{Dio} K \mathrm{KO}(\mathrm{n}=8)$ and Mct8/Dio2KO $(\mathrm{n}=9)$ mice at 6 months of age. Measures were obtained by specific radioimmunoassays. Data are expressed as mean $\pm \mathrm{SE}$ and $* p<0.05,{ }^{* *} p<0.01$, and $* * * p$ $<0.001$ were determined by one-way analysis of variance (ANOVA) and Bonferroni's post hoc test. 


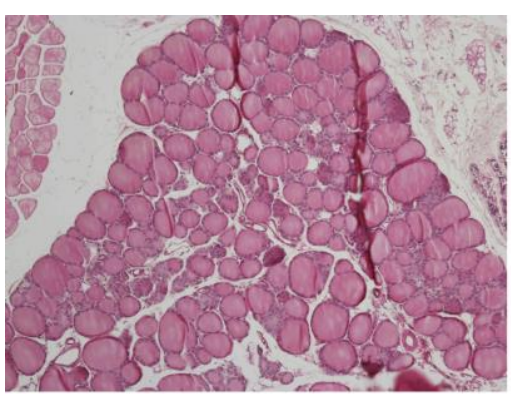

Wt

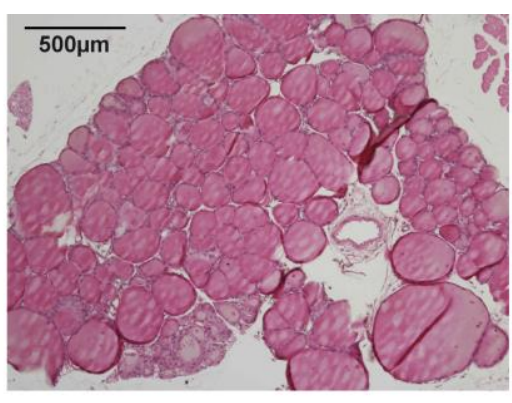

Mct8/Dio2KO

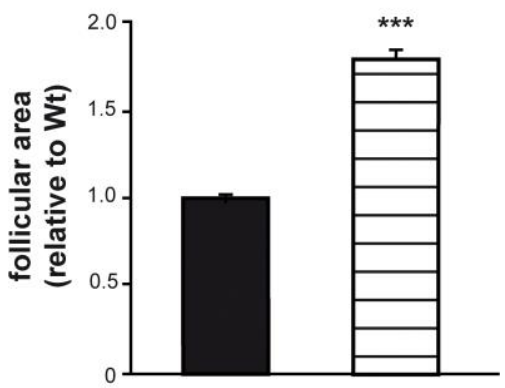

Wt Mct8/Dio2KO

Figure 2. Thyroid gland histology of $\mathrm{Wt}$ and Mct8/Dio2KO mice. Thyroid glands sections from Wt $(n=4)$ and Mct8/Dio2KO mice $(n=4)$ at 6 months of age were stained with hematoxylin and eosin. The area of 50 follicles was measured in four slices for each animal. Data represent the mean of the follicle size $( \pm S E M)$ and are expressed relative to $\mathrm{Wt} .{ }^{* * *} \mathrm{p}$ $<0.001$ determined by Student's t-test. 
A

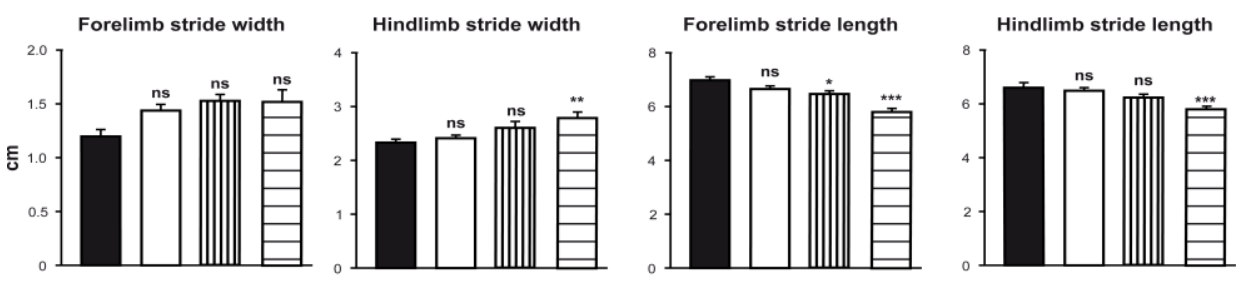

B

Forelimb stride width

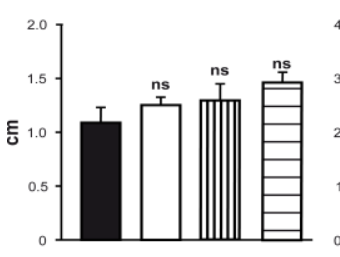

3 months

을

Figure 3. Abnormal gait in Mct8/Dio2KO mice. Forelimb and hindlimb stride width and forelimb and hindlimb stride length in Wt $(n=10)$, Mct8KO $(n=8)$, Dio2KO $(n=8)$ and Mct8/Dio2KO $(n=10)$ mice at 3 months of age and in Wt $(n=10)$, Mct8KO $(n=8)$, Dio2KO $(\mathrm{n}=8)$ and Mct8/Dio2KO $(\mathrm{n}=9)$ mice at 6 months of age, based on footprint analysis. Data are expressed as mean \pm SE and $* p<0.05, * * p<0.01$, and $* * * p<0.001$ were determined by ANOVA and Bonferroni's post hoc test. 

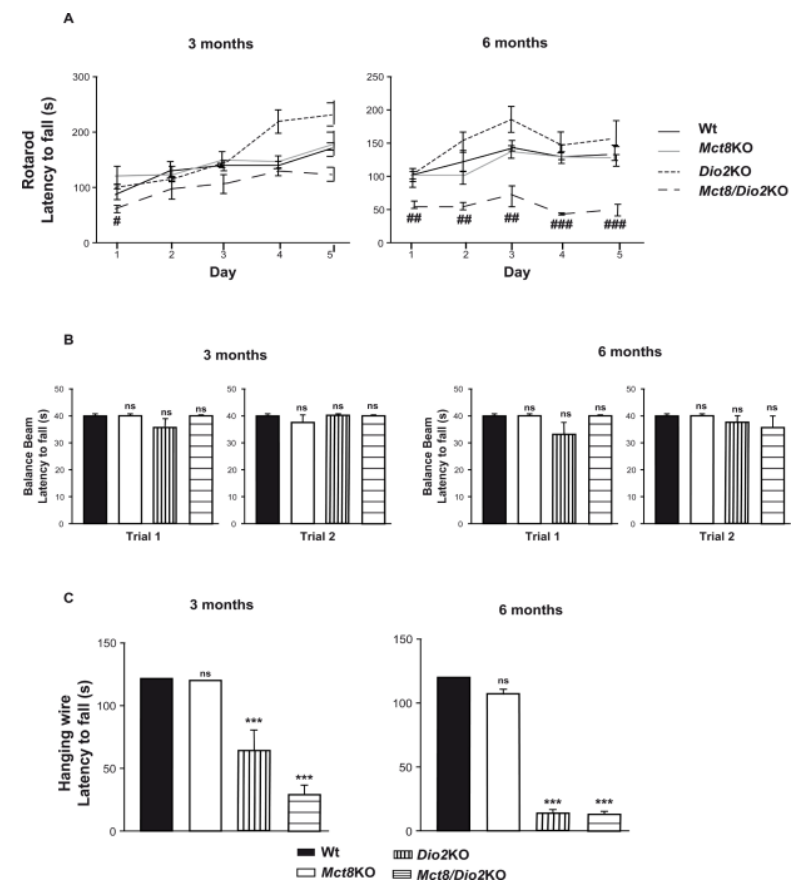

Figure 4. Motor skill impairments in Mct8/Dio2KO mice. (A) Latency of Wt $(\mathrm{n}=10)$, $\operatorname{Mct8KO}(n=8), \operatorname{Dio} 2 K O(n=8)$ and Mct8/Dio2KO $(n=10)$ at 3 months of age and of Wt (n $=10), \operatorname{Mct8KO}(n=8), \operatorname{Dio} 2 \mathrm{KO}(\mathrm{n}=8)$ and Mct8/Dio2KO $(\mathrm{n}=9)$ mice at 6 months of age to fall from the rod in the rotarod test. Data are expressed as mean \pm SE in each of the 5 days of the test and analysed by general linear models. \# $p<0.05 ; \# \# p<0.01$ and \#\#\#p $<0.001$ were determined by Student's t-test between Wt and Mct8/Dio2KO animals. (B) Latency to fall from the beam during the balance beam test in two trials and $(C)$ latency to fall off the grid in the hanging wire test in Wt $(n=10), \operatorname{Mct8KO}(n=8), \operatorname{Dio} 2 \mathrm{KO}(\mathrm{n}=8)$ and Mct8/Dio2KO $(n=10)$ mice at 3 months of age and in Wt $(n=10)$, Mct8KO $(n=8)$, Dio2KO $(\mathrm{n}=8)$ and Mct8/Dio2KO $(\mathrm{n}=9)$ mice 6 months of age. Data are expressed as mean $\pm \mathrm{SE}$ and $* * * p<0.001$ was determined by ANOVA and Bonferroni's post hoc test. 
Parvalbumin (3 months)

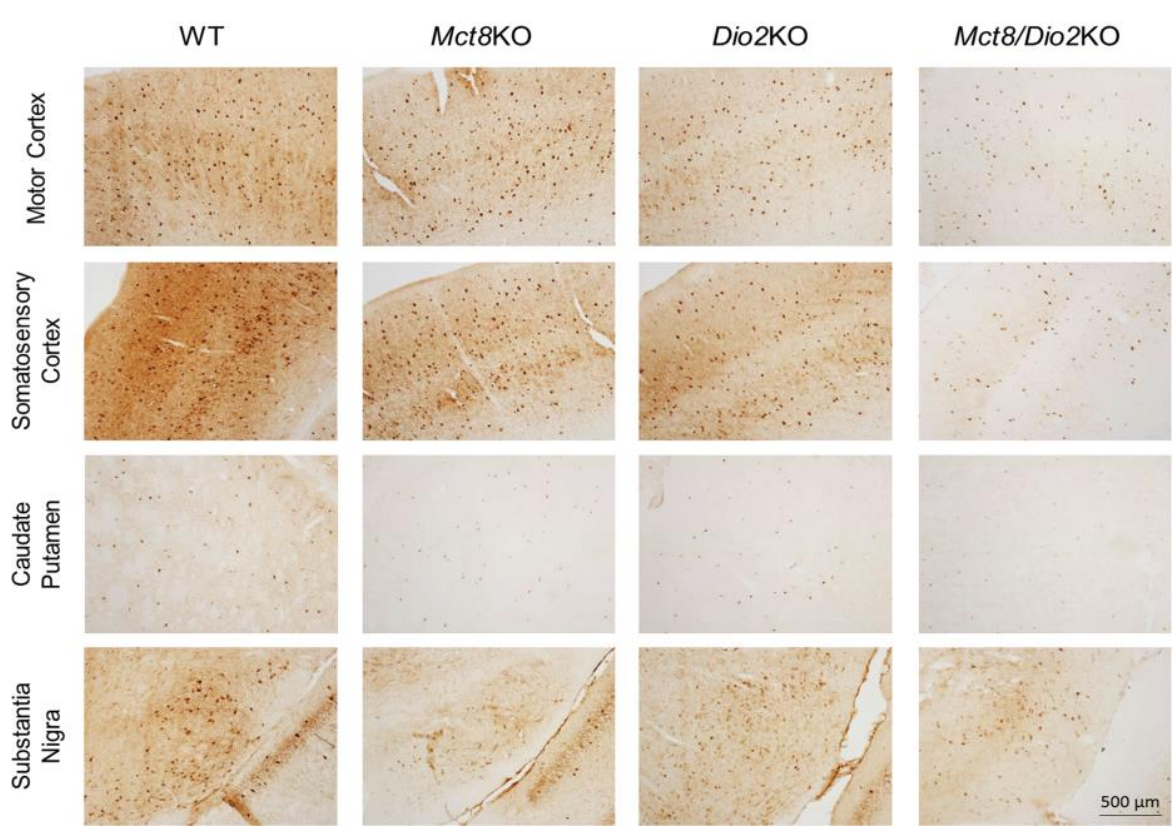

Figure 5. Altered Parvalbumin expression in 3-month old Mct8/Dio2KO mice. Brain coronal sections of Wt $(n=4), \operatorname{Mct8KO}(n=4)$, Dio2KO $(n=4)$ and Mct8/Dio2KO $(n=4)$ mice were immunostained with anti-Pvalb. Representative images showing the immunostaing pattern in different regions of the cerebral cortex (motor and somatosensorial cortex) and basal ganglia (caudate-putamen and substantia nigra). Pvalb immunostaining intensity was strongly decreased in all the regions in Mct8/Dio2KO mice in comparison to Wt. Sections of Mct8KO and Dio2KO mice also showed a reduction in the staining pattern but much less pronounced than in Mct8/Dio2KO animals. 


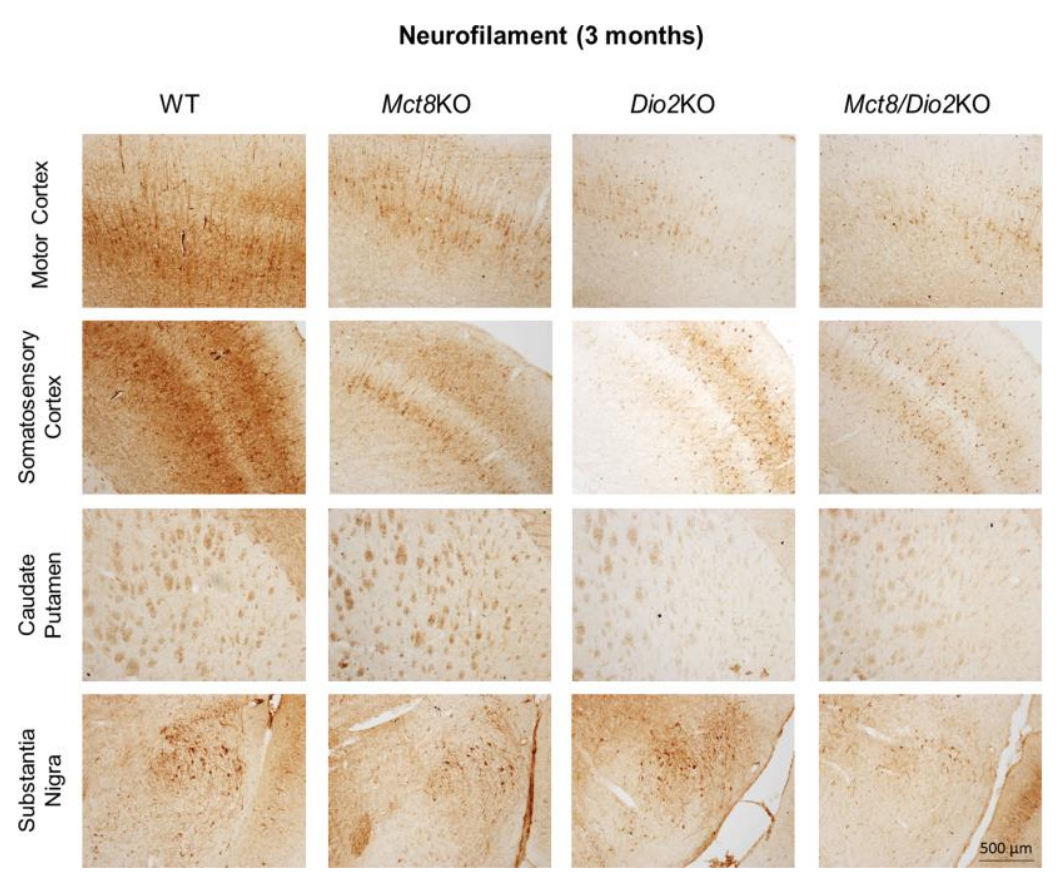

Figure 6. Altered Neurofilament 220KD expression in 3-month old Mct8/Dio2KO mice. Representative images of brain coronal sections of Wt $(n=4), \operatorname{Mct} 8 \mathrm{KO}(n=4), \operatorname{Dio} 2 \mathrm{KO}(\mathrm{n}=$ 4) and Mct8/Dio2KO $(\mathrm{n}=4)$ mice immunostained with anti-Nefh. Mct8/Dio2KO mice showed a markedly reduced staining especially in the motor cortex and substantia nigra. Mct8KO and Dio2KO mice also showed a decreased immunostaining intensity in the cerebral cortex (motor and somatosensory cortex) but in to lesser extent than Mct8/Dio2KO mice. In basal ganglia (caudate-putamen and substantia nigra) Mct8KO and Dio2KO mice showed a Nefh-staining pattern similar to Wt animals. 